\title{
INHERENT FREEZE PROTECTION FOR SOLAR WATER HEATERS
}

Prepared for

\author{
Supported by \\ Grant DE-FG4480RF.10114.000
}

by

Sheldon $M$. Jeter

Lance $L$. Leonaitis

Lawrence L. Leonaitis

May, 1981 


\section{DISCLAIMER}

This report was prepared as an account of work sponsored by an agency of the United States Government. Neither the United States Government nor any agency Thereof, nor any of their employees, makes any warranty, express or implied, or assumes any legal liability or responsibility for the accuracy, completeness, or usefulness of any information, apparatus, product, or process disclosed, or represents that its use would not infringe privately owned rights. Reference herein to any specific commercial product, process, or service by trade name, trademark, manufacturer, or otherwise does not necessarily constitute or imply its endorsement, recommendation, or favoring by the United States Government or any agency thereof. The views and opinions of authors expressed herein do not necessarily state or reflect those of the United States Government or any agency thereof. 


\section{DISCLAIMER}

Portions of this document may be illegible in electronic image products. Images are produced from the best available original document. 
Abstract

Introduction and Executive Summary

Preliminary Work

Mathematical Analysis

Small Scale Freeze Test

Water Absorption Test

Compressibility Test

Strain Analysis

Absorber Freeze Test

Freeze Test Chamber

Prototype Testing

Design Review 
ABSTRACT

Research and development of a method for protection of a solar collector from freezing is described. The method is shown to be technically and economically feasible. A prototype water heating system using the inherent freeze protection method was successfully operated during the winter of 1980-1981. 
Introduction and Executive Summary

This report describes the successful conduct of research supported by Appropriate Technology Grant DE-FG4480RF.10114.000 for the development of a method for inherent freeze protection for solar collectors (specifically solar water heaters).

Nearly all the generally-recognized problems associated with solar water heaters are caused or exaserbated by the need to protect the exposed collector panel and its associated piping from freezing. A few of these problems can be itemized to illustrate the impact of this problem:

(1) The expense of separate water/freeze-suppressent loops and the associated complexity in controls and auxiliaries

(2) The unreliability of drain-back and recirculation systems

(3) The materials problems encountered in high-temperature situations especially in drain-back systems

(4) The difficulty of integrating thermosyphon collectors into conventional freeze-protection systems

These and many other problems indicate that once again conventional techniques and standard procedures are ineffective in producing solar utilization systems that have acceptable performance and cost. 
The innovative concept described in this report is inherent freeze protection by including a compliant element in all exposed piping. No attempt is made to overwhelm the freezing phenomenon. Rather, freezing is allowed to occur and the resulting expansion is accomodated by compression of the compliant element. If the element is appropriately sized, the expansion of the freezing water will be accomodated without excessively stressing the water tubes. Currently the compliant element being tested is a circular polymer-foam rod.

This research project included several stages of technology review, analysis, design, testing, and demonstration described in detail in the following. In sumary, candidate materials were reviewed and a commercial product selected for use. After preliminary analysis, a series of small-scale tests were conducted to prove the concept and evaluate the suitability lagainst water absorption and thermal degradation) of the material. A full-scale absorber test under controlled conditions was run and repeated to further evaluate and verify the concept. Then a full-scale prototype was constructed and operated during a nearly-complete winter season.

The result of this work is a demonstrated method for inherent freeze protection. As the concept is developed today, it is suitable for low pressure active or thermosyphon systems. Some further work is indicated to meet the requirements of high-pressure systems and to use lower cost polymers. 
PRELIMINARY WORK

Survey of Materials

The concept of the inherently freeze protected solar collector requires a compressible inner element. This inner element must be flexible to absorb the expansion of water as it changes phase from liquid to solid and then rebound when the ice reverts to water. The compliant member must also be able to withstand the temperature extremes that a collector panel will be subjected to. The lowest temperature that can reasonably be expected is about $-30^{\circ} \mathrm{F}$ which regularly occurs in the northern states of the contiguous United States. The greatest temperature that can be expected occurs during. stagnation. This condition is one of no fluid flow, hence heat removal is zero, on a hot sunny day. For a single glazed, well insulated collector. with an absorber plate that is flat black, the maximum stagnation temperature that can be expected is about $300-325^{\circ} \mathrm{F}$. A double glazed collector with a selectively coated absorber can be expected to reach $350-400^{\circ} \mathrm{F}$.

This work is orienled towards residential solar water heaters. Collectors with a single glazing and a flat black absorber are standard for this application and hence a stagnation temperature of $320^{\circ} \mathrm{F}$ is used to define the upper temperature limit. 
An option for consideration is to limit the upper temperature to $250^{\circ} \mathrm{F}$. this assumes that the collector is always flooded with water. On stagnation, a temperature relief valve releases steam when the water in the panel reaches $250^{\circ} \mathrm{F}$. Make up water the cools the collector. The temperature limit of $250^{\circ} \mathrm{F}$ will be examined as a reasonable but less restrictive limit than the $320^{\circ} \mathrm{F}$.

A further requirement of the compressible member is that the material not be significantly permeable to water.

The requirements of $320^{\circ} \mathrm{F}$ and nonpermeability with respect to water restrict the field of candidate materials.

The final requirement that the compressible member be a foamed rod of a suitable material was found to reduce the field of candidates to one choice. This is silicone. Foamed silicon rod is used as a gasketing material in 0-rings and other similar applications. It is made in a variety of densities and diameters. The foamed rod is not a stocked item and is generally made to order by specifying the density (or void fraction), the diameter and other factors which determines the exact polymer of silicon to use.

After contacting over two dozen manufacturers only one did appreciable manufacturing work with this particular form of silicon who was willing to work with us. Groyndyke Manufacturing agreed to send us samples it had in inventory from order over runs and samples of work it was currently running. These samples were used in the small scale freeze testing. 
After selection of two candidate sizes, they had sufficient over run from an order to supply one size. The other size had to be custom run for us. Small quantity runs are expensive due to set up costs. The rod itself is fairly inexpensive per foot as it is mostly air. The cost per foot is between 4 and 7 cents per foot depending on diameter and density.

A sample of foamed neoprene was procured as a fall back option. The neoprene is only useful up to $250^{\circ} \mathrm{F}$. It cost between 2 and 4 cents per foot depending on diameter and density. Inherently, low temperature applications abound wherein this material might be used; however, silicone rod was selected as the only generally-applicable material. 
Mathematical Analysis

The aim of this mathematical analysis is to predict the final pressure in a frozen pipe protected by a compliant element or inversely to determine the dimensions of a compliant element for limiting the ultimate pressure in a frozen pipe to some predetermined value. No attempt is made to model the kinetics or detailed mechanism of the freezing process because it appears to be immaterial to the engineering of the compliant element.

This analysis is based on the simple geometry illustrated in the attached figures. Three states are shown:

(1) The as-received compliant element or core which is illustrated as a tube with walls of appreciable thickness. This is not the current method of implementing the compliant element since the presently preferred method is to utilize the compressibility of a gas (air) dispersed in a closed-cell foam where the encapsulant is a polymer. The representation of the compliant structure as a tube is fully adequate, however, since the state (volume and pressure) of the gas is insensitive as to whether it is confined to a set of irregular cells or a single cylindrical volume. The resulting geometry is much simplier. The element is a tube of outer diameter $d_{0}$ and inner diameter $x_{0}$ as fabricated. The confined air is at pressure $P_{0}$ and ambient temperature $\left(T_{0}\right.$, assumed $\left.70^{\circ} \mathrm{F}\right)$. The tube is an incompressible material (the polymer encapsulant). 
(2) The second illustration is the encapulated gas inside the rigid watcr-filled pipe at the onset of freezing. Pressure in the water is $P_{L}$ (line pressure) and the prevailing temperature is freezing - $\left(0^{\circ} \mathrm{F}\right)$. The rigid water pipe has inner diameter $D$. In this state, the greater pressure $P_{L}$ external to the compliant core element will have reduced outer diameter $d$; and since the incompressible encapsulant occupies a fixed volume, the gas is confined to a smaller volume represented by the diameter $x$. The gas is at freezing $T$ and $P_{1}$

(3) During freezing, the conservative assumption is made that a fixed quantity of water remains in the pipe. The third illustration shows the increased cross section area occupied by ice and the reduced outer diameter of the compliant core $d_{2}$. Because the encapsulant maintains a fixed volume, the diameter of the gas pocket is reduced to $x_{2}$. Pressure in the ice is $P_{2}$,

Certain assumptions are necessary concerning the mechanical properties of the ice and encapsuldnt. (The water is considered as just an incompressible liquid, and the gas an ideal gas.) It is anticipated that a polymer encapsulant will be used. If the actual structure is a closed-cell foam, or even if a thick-walled tube is used, the encapsulant is reasonably assumed to have no strength in compression. This means that in the initial state the confined gas may have a pressure greater than ambient pressure thus stressing the encapsulant. In the present analysis, the encapsulant is taken as stress free, but as shown in the appendix, it's easy to extend to the case of an initial pressure above ambient. 
It is anticipated that the line pressure will exceed the initial pressure in the gas, consequently, the tube will be under compression in the second state, and the encapsulant will be conveniently assumed stress-free. The same assumption is taken without reservation at the much higher final pressure after freezing. These assusmptions result in a uniform pressure in the water and gas in state 2 and ice and gas in state 3 . The ice is assumed to behave as a fluid during freezing so that no shear stress is developed. This is in agreement with the observed mechanism of freezing in which delicate needless of dendritic crystals first fill the volume. These crystals can sustain no bending as they aggomerate into a solid; therefore, it is reasonable to ignore any mechanical effects during freezing other than a uniform expansion.

The system under consideration is a long pipe containing water and the compliant core. During freezing no water escapes. This is a conservative assumption, and if in practice some water is forced from the pipe a lower ultimate pressure will result. Before freezing the total volume comprises the volume of water, encapsulant, and gas:

$$
\begin{aligned}
& V_{T}=V_{w}+V_{e}+V_{1} \\
& V_{T}=L A_{T}=L\left(A_{W}+A_{e}+A_{1}\right) \\
& V_{T}, A_{T}=\text { total volume, cross-section } \\
& V_{W}, A_{W}=\text { volume, cross-section, occupied by water }
\end{aligned}
$$




$$
\begin{aligned}
& v_{e}, A_{e}=\text { volume, cross-section, occupied by encapsulant } \\
& V_{1}, A_{1}=\text { volume, cross-section, occupied by gas (at } P_{1}, T_{1} \text { ) } \\
& L=\text { length of pipe }
\end{aligned}
$$

Similary, after freezing:

$$
A_{T}=A_{j}+A_{e}+A_{2}
$$

where:

$$
\begin{aligned}
& A_{i}=\text { cross-section occupied by } i c e \\
& A_{e}=\text { fixed } \\
& A_{2}=\text { cross-section occupied by gas (at } P_{2}, T_{2} \text { ) }
\end{aligned}
$$

Currently it is assumed that the compliant core is fabricated at ambient pressure, $P_{0}=P(a t m)$, and that $P_{L}$ is greater than $P_{0}$ so the encapsulant is stress free in the pipe allowing the assumption:

$$
\begin{aligned}
& P_{1}=P_{L} \\
& P_{2}=P_{i}
\end{aligned}
$$

the mass of water is constant so:

$$
m(\text { water })=\frac{v_{i}}{v_{i}}=\frac{v_{w}}{v_{w}}
$$




$$
v_{i}=\frac{v_{i}}{V_{w}} V_{w}=1.09 v_{w}
$$

and

$$
A_{i}=1.09 A_{w}
$$

Similary for the air:

$$
\frac{R_{m} \text { (air) }}{L}=\frac{A_{0} P_{0}}{T_{0}}=\frac{A_{1} P_{1}}{T_{1}}=\frac{A_{2} P_{2}}{T_{2}}
$$

Where these equations relate conditions as received, at the onset of freezing, and as freezing is completed.

Since the pipe is rigid,

$$
A_{w}+A_{p}+A_{1}=A_{i}+A_{e}+A_{2}
$$

and since the encapsulant occupies a fixed volume,

$$
A_{w}+A_{1}=1.09 A_{w}+A_{2}
$$

Using the ideal gas law,

$$
A_{w}+A_{1}=1.09 A_{w}+A_{1}\left(P_{1} T_{2} / P_{2} T_{1}\right)
$$


First, consider a case where $A_{p}$ is negligible:

$$
\begin{aligned}
& A_{w}=\pi\left(D^{2}-d^{2}\right) / 4 \\
& A_{1}=\pi d^{2} / 4 \\
& d^{2}=.09 D^{2}\left(1.09-P_{1} T_{2} /\left(P_{2} T_{1}\right)^{-1} .\right.
\end{aligned}
$$

the preceding assumes nothing but a uniform expansion of the ice and a stress-free condition of the encapsulant after freezing $\left(P_{2}=P(i c e)\right)$. If the as-received pressure in the core is $P_{0}$ then,

$$
d^{2}=d_{0}^{2} \frac{P_{0} T_{1}}{P_{1} T_{0}}
$$

If $P_{0}$ exceeds atmospheric pressure then consideration of the mechanical properties (or direct measurement) is necessary to relate $P_{0}$ to the atmospheric pressure. Similary if $P_{1}$ exceeds $P_{L}$ analysis of the strain in the encapsulant is necessary.

Next, consider the case where the encapsulant occupies an appreciable volume

$$
\begin{aligned}
& \left(1-P_{1} T_{2} /\left(P_{2} T_{1}\right)\right) A_{1}=0.09 A_{w} \\
& \left(1-P_{1} T_{2} /\left(P_{2} T_{1}\right)\right) x^{2}=0.09\left(D^{2}-d^{2}\right),
\end{aligned}
$$

and since the volume of encapsulant is fixed

$$
d^{2}-x^{2}=d_{0}^{2}-x_{0}^{2}
$$


Since the mass of gas is fixed:

$$
\begin{aligned}
& x^{2}=x_{0}^{2} P_{0} T_{1} /\left(P_{1} T_{0}\right) \\
& x_{2}^{2}=x_{0}^{2} P_{0} T_{2} /\left(P_{2} T_{0}\right)
\end{aligned}
$$

Substituting for $x^{2}$ in the equation for $d^{2}$ yields

$$
d^{2}=d_{0}^{2}-x_{0}^{2}\left(1-P_{0} T_{1} /\left(P_{1} / T_{0}\right)\right)
$$

Finally, $x_{0}$ can be determined

$$
\begin{aligned}
& \left(\left(1.09-P_{1} / P_{2}\right)\left(P_{0} T_{1} / P_{1} T_{0}\right)+.09\left(d_{0}^{2} / x_{0}^{2}-1\right)\right) . \\
& x_{0}^{2}=.09 D^{2}
\end{aligned}
$$

If $x_{0}=d_{0}$ the preceding result for negligible $A_{e}$ is regained.

It's convenient to assume that $P_{0}$ is $P(a t m)$ and that $P_{1}$ is $P(1$ ine); however, it is not necessary as shown in the appendix.

To complete the analysis it is necessary to define the tubular geometry by the ratin $x_{0} / d_{0}$. If actual tubing is used, this ratio is simply the ratio of inside to outside diameter in the initial state. 
The core could be defined by the mass fraction of gas:

$$
\begin{aligned}
& f=m(\text { air }) / m(\text { total }) \\
& x_{0}^{2} / d_{o}^{2}=f\left(f_{e} / \rho_{g}\right) /\left(1-f+f \rho_{e} / \rho_{g}\right) \\
& \text { where } \rho_{e}=\text { density of encapsulant } \\
& \rho_{g}=\text { density of gas }
\end{aligned}
$$

Definition by this method would appear straight forward, but the experimental determination is difficult without independent determination of $P_{e}$.

A preferred core definition is the volume fraction of encapsulant. This fraction may be inferred from the results of the compressibility test described below or possibly determined by direct measurement. If this fraction, $V_{e} / V_{0}$, is known, the diameter ratio in the initial state can be evaluated from the following:

$$
x_{0}^{2} / d_{0}^{2} \equiv 1.0-v_{e} / v_{0}
$$

Following are a sample of computer outputs giving the required core size (initial core OD) to limit the ultimate pressure in the pipe to the maximum allowable for annealed 5/8 inch copper ACR tube as used in the prototype. In each case, the initial pressure in the gas is one atmosphere. Also given are the core $O D$ at line pressure and the onset of freezing and core $O D$ after freezing is complete. Hypothetical core inner diameters, as if the core were 
a hollow tube, are also given. The pressure in the gas at onset of freezing, $P_{1}$, is the line pressure for this case. A listing of program FREEZE, which generated these results, is also given.

Although the results of the compressibility tests were ambiguous because of experimental difficulties, an encapsulant volume fraction around 0.1 seems representative. Inspection of the computer output for this volume fraction indicate that the $5 / 16(0.3125)$ in $O D$ core should protect the absorber tube at low pressure. This is confirmed by the successful absorber freezing and prototype tests. The higher pressure $(60$ psig) absorber freezing test confirms that an initially unpressurized $\left(p_{0}=1 \mathrm{~atm}\right) 5 / 16$ in. core is inadequate for line pressure encountered in common practice. 
Appendix

In the preceding analysis it was assumed that the initial pressure $P_{0}$ and pressure at the onset of freezing $P_{1}$ in the encapsulated gas were known. Such would be the case for example if the encapsulant were initially stress-free $\left(P_{0}=\right.$ ambient pressure, $\left.P_{a}\right)$ and as is usual $P_{L}=P_{a}$ (so that $P_{1}=P_{L}$.

In a more general case, the encapsulant might be stressed. The preceding analysis can be easily extended by assuming that the encapsulant acts as a thin-walled cylinder. Initially assume the gas is at some pressure greater than $P_{a}$. The stress in the encapsulant is then:

$$
\begin{aligned}
& \sigma_{0}=\left(P_{0}-P_{a}\right) x_{0} /(2 t) \\
& t=\text { thickness of encapsulant wall }
\end{aligned}
$$

the circumferential strain is then:

$$
\begin{aligned}
& E_{0}=\sigma_{0} / E=\left(x_{0}-x_{a}\right) / x_{a} \\
& E=\text { Youngs modulus of the encapsulant }
\end{aligned}
$$$$
x_{a}=\text { relaxed, stress-free diameter of core }
$$ 
And the initial diameter can be determined from the relaxed diameter:

$$
x_{0}=x_{a} /\left(1.0-\left(P_{0}-P_{a}\right) x_{a} /(2 t E)\right) \text { where } P_{0}=P_{a}
$$

For a given encapsulant tube construction $\left(t\right.$ and $x_{a}$ ) the initial diameter can be determined if the elastic modulus of the material is known.

If $P_{1} P_{L}$ (which is unlikely), then $P_{1}$ and $x$ would be unknown but can be determined by simultaneous solution of the coupled equations.

$$
\begin{aligned}
& x=x_{a} /\left(1.0-\left(P_{1}-P_{L}\right) x_{a} /(2 t E)\right) \text { where } P_{1}=P_{L} \\
& x^{2}=x_{0}^{2} P_{0} T_{1} /\left(P_{1} T_{0}\right)
\end{aligned}
$$


SMALL SCALE FREEZE TEST

\section{Description of Procedure}

The small scale freeze test was a low cost approach to attempt to validate the mathematic analysis that was used in selecting the compressible members's density and diameter and to verify the basic concept.

Three pipe sizes were selected as candidates based on possible bending diameters and functional considerations. These sizes were 5/16", 1/2", and $5 / 8$ " type $L$ water pipe. In refrigeration, pipe sizes they were $1 / 2 ", 5 / 8$ " and $3 / 4 "$. Henceforth, they will be referred to by their water pipe size.

Seven lengths of each pipe were cut to seven foot lengths lexcept for the $5 / 16^{\prime \prime}$ pipe, only 3 were cut of it). They were bent $180^{\circ}$ at the center with a pipe bender to assure a constant cross sectional profile. Each end was fitted with an adapter onto which a plug valve could be threaded. Each of the fourteen pipes were fitted with samples of the compressible rod. They were loaded as follows:

\section{Compressible Rod Diameter}

$$
\text { O" } 1 / 4^{\prime \prime} \quad 5 / 16^{\prime \prime} \quad 3 / 8^{\prime \prime}
$$

$\begin{array}{lllll}\text { 3/16" PIPE } & 1 & 2 & 0 & 0 \\ \text { 1/2" PIPE } & 1 & 2 & 2 & 2 \\ 5 / 8 \text { " PIPE } & 1 & 2 & 2 & 2\end{array}$


The seventeen tubes were fitted with plug cocks and flushed with water to insure that no air remained. On flushing several of the $1 / 4$ " compressible elements extruded out when the water flow was too high. This created a problem in feeding the compressible member back through the wetted pipe. This problem was again encountered and resolved in the absorber plate test.

After flushing the air out of each tube, the plug valves were shut. All seventeen samples were coded to intensify the sample held within and marked at the center of each $\log$ so that measurements could be taken at the same location after each successive freezing. The diameter of both legs of all samples were taken and placed in a freezer.

The samples were left in the freezer for at least 10 hours, they were removed, allowed to warm up to room temperature for about 30 minutes, and then the diameters were remeasured. Any tubes that ruptured were no longer freeze cycled. Before each sample was returned to the freezer the tubes were topped off with water to fill the increase in volume caused by expansion of the tube from freeze damage. This process was continued for thirty cycles. In some instances, the samplcs remained frozen for well over ten hours.

Summary of Results

All samples without the compressible member ruptured after the first freeze cycle except one, the 5/16" pipe ruptured on the second cycle. Progressive swelling occurred on the $1 / 2^{\prime \prime}$ and $5 / 8^{\prime \prime}$ pipe with the $1 / 4^{\prime \prime}$ compressible element and the 5/8" pipe with the 5/16" compressible element. All of these were cycled to ultimate failure. The rate of swelling increased on these samples up to rupture. 


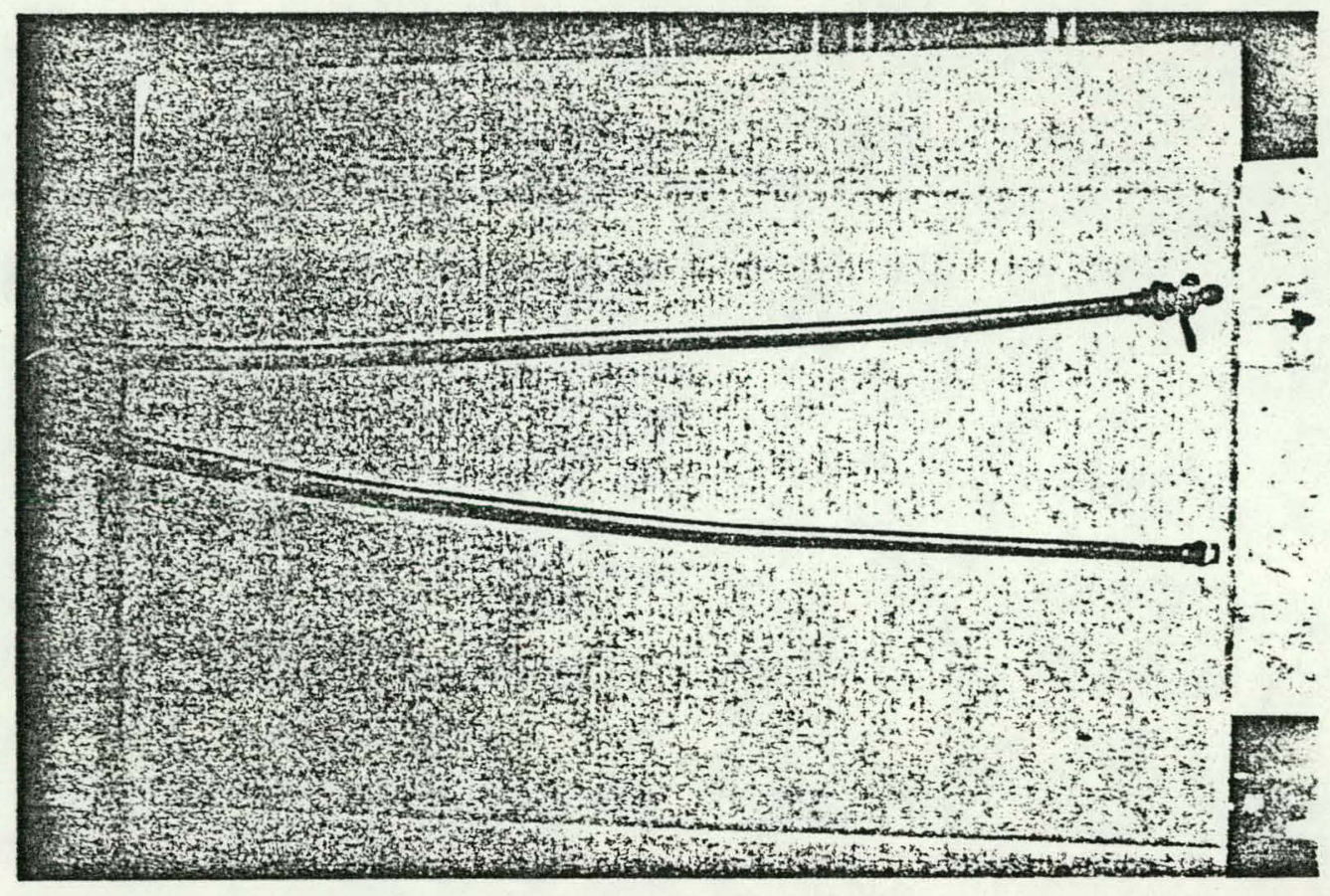

'Fig. 1: Typical Small Scale Freeze Test Article $\left(180^{\circ}\right.$ bend)

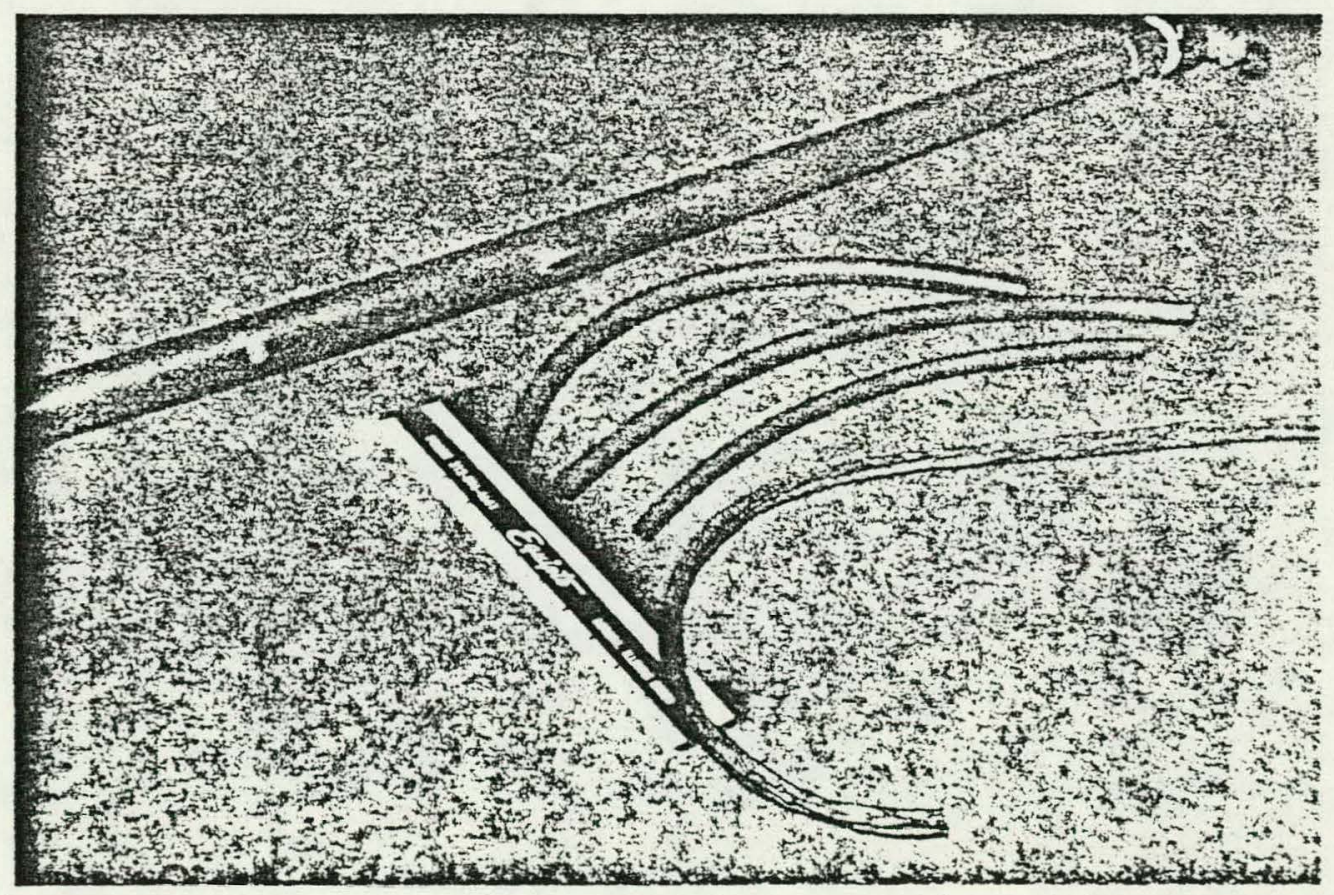

Fig. 2: 5/8 in. Pipe Sample After Cycling to Failure. Note Original Inserts of Various Diameters and Collapsed Insert After Failure 
After five cycles, swelling was measured in one leg of a $1 / 2$ " pipe with the $5 / 16^{\prime \prime}$ rod. It ruptured after eight cycles extruding part of the compliant member out of the rupture hole.

No changes in pipe diameters were detected in any sample with the $3 / 8^{\prime \prime}$ compressible element or in the second $1 / 2^{\prime \prime}$ pipe with the $5 / 16^{\prime \prime}$ compressible element after thirty cycles.

Four more test cells of the $1 / 2^{\prime \prime}$ tube were made and loaded with the 5/16" compressible rod. No measurable expansion occurred after fifteen freeze cycles.

Conclusion: The failure of the one $1 / 2^{\prime \prime}$ pipe with the $5 / 16^{\prime \prime}$ rod could not be repeated. The postulated cause is that the pipe had a reduction in wall thickness, a manufacturing defect, at the location of the failure. This has not been validated.

The $1 / 2^{\prime \prime}$ pipe was selected because of it's relative low cost to the $5 / 8$ " pipe, it is standard size pipe in the plumbing industry whereas $5 / 8$ " pipe (3/4" refrigeration tube) is not used in plumbing.

The $5 / 16^{\prime \prime}$ compressible element was chosen as the one failure could not be repeated and the $3 / 8^{\prime \prime}$ compressible member might constitute a significant pressure drop for flow in the $1 / 2$ " pipe.

Final selection was $1 / 2^{\prime \prime}$ I.D. type $L$ copper pipe with $5 / 16$ " OD silicon foam rod. 


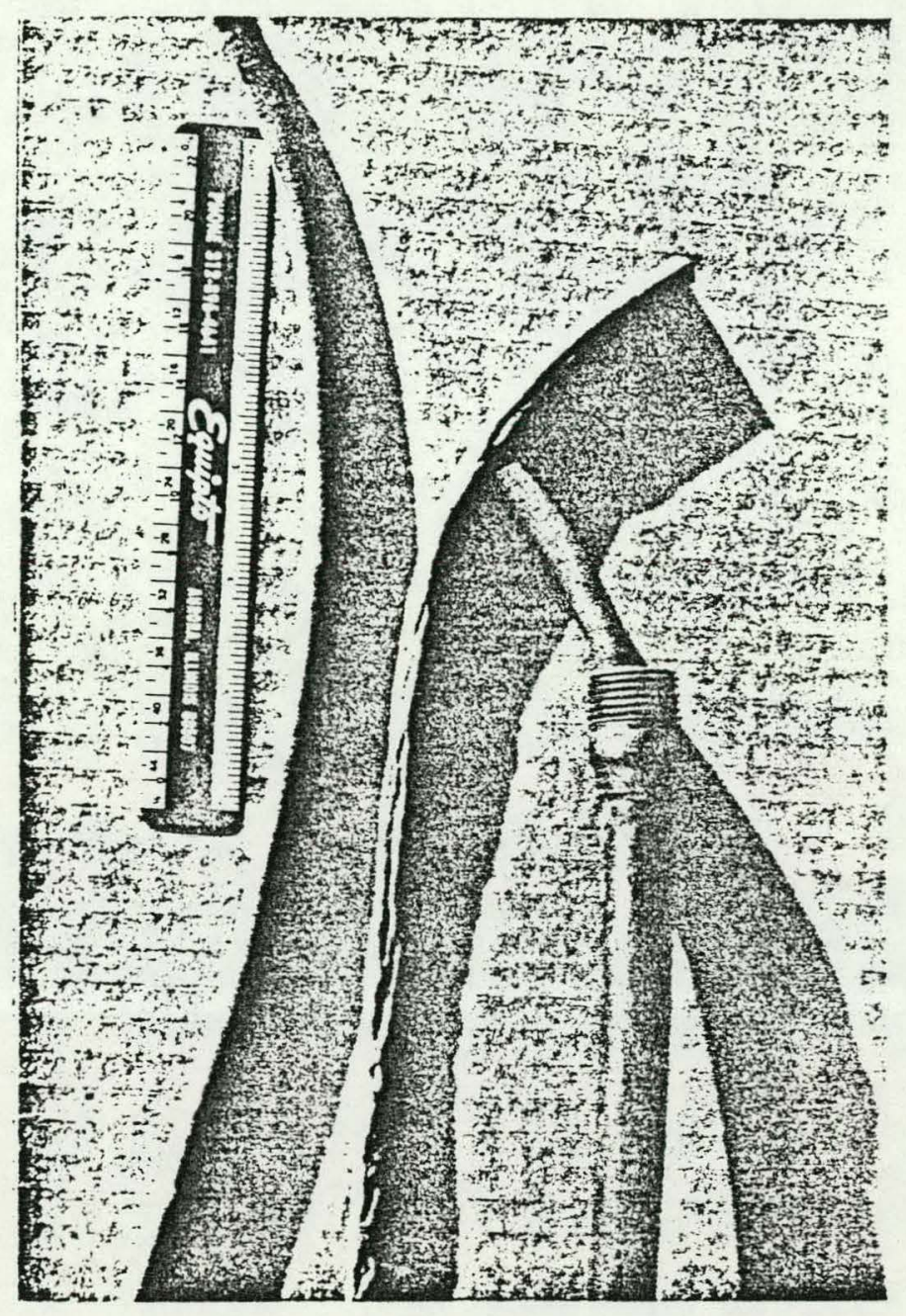

Fig. 3: Example of Test Articles and Inserts. Note insert with air cells collapsed from enormous pressure encountered in freezing to pipe failure. 
WATER ABSORPTION TEST

\section{Test Procedure}

For the compressible element to maintain its usefulness over time, it must not absorb water. The absorption of water would indicate that compressible air was being slowly replaced by non-compressible water. In order to determine if this is a problem with the silicon rod, an absorption test was conducted.

This test consisted of cutting four samples of the $5 / 16^{\prime \prime}$ foam rod $48^{\prime \prime} 1$ ong. Each sample was then weighed. A conventional cooking "crock pot" was half filled with water and setting was selected that would maintain the water at $180^{\circ} \mathrm{F}$. The four samples were submerged by placing a weighted screen on top of them.

The four samples were removed from the "crock pot," placed on a towel, lightly blotted dry, and allowed to air dry at room temperature for ten minutes. The sample was then reweighed and replaced in the "crock pot" which remained set to maintain the water at $180^{\circ} \mathrm{F}$. These steps are conducted after 1 month, 2 months, and 4 months. 


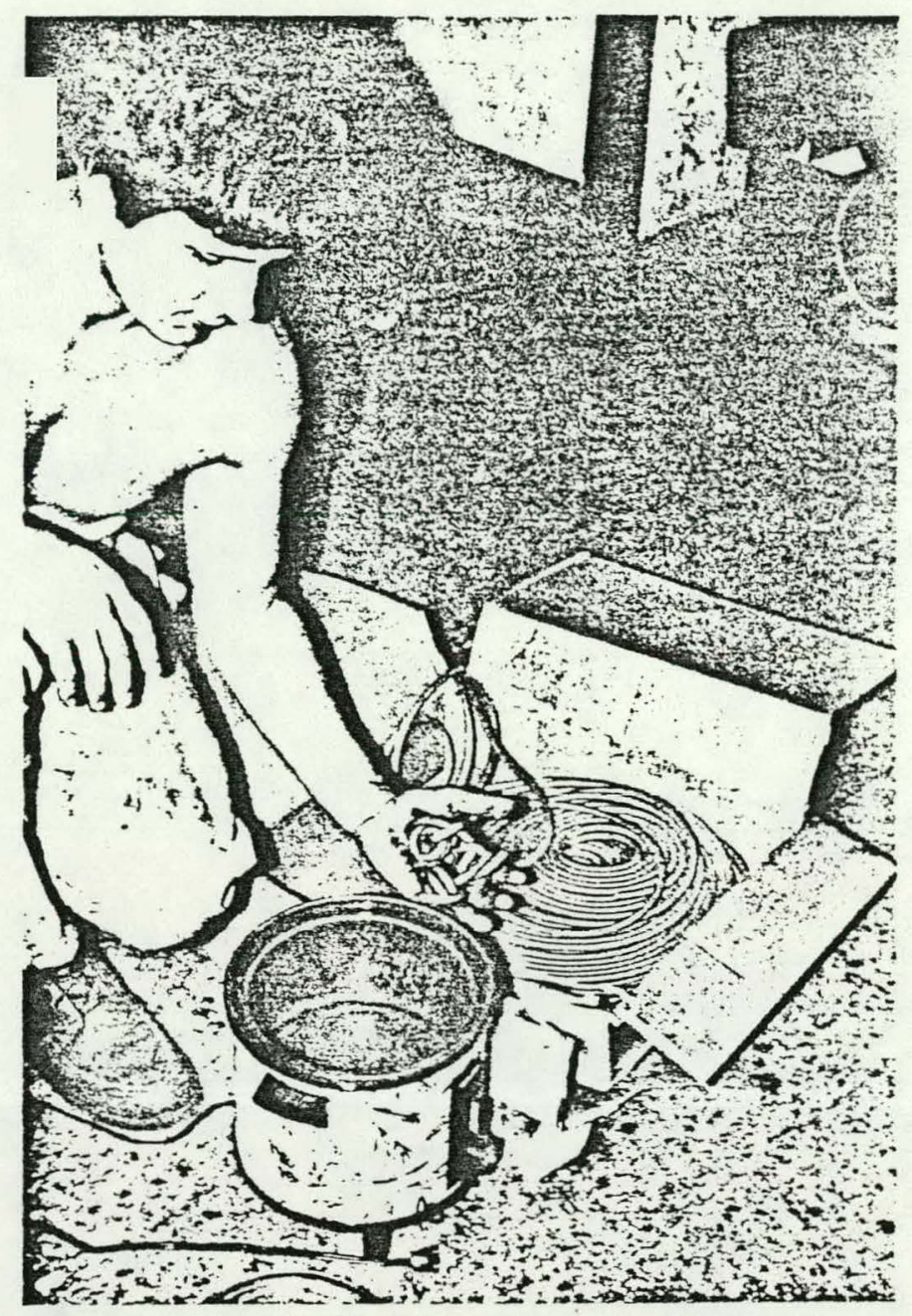

Fig. 4: Samples and Heater for Absorption Test

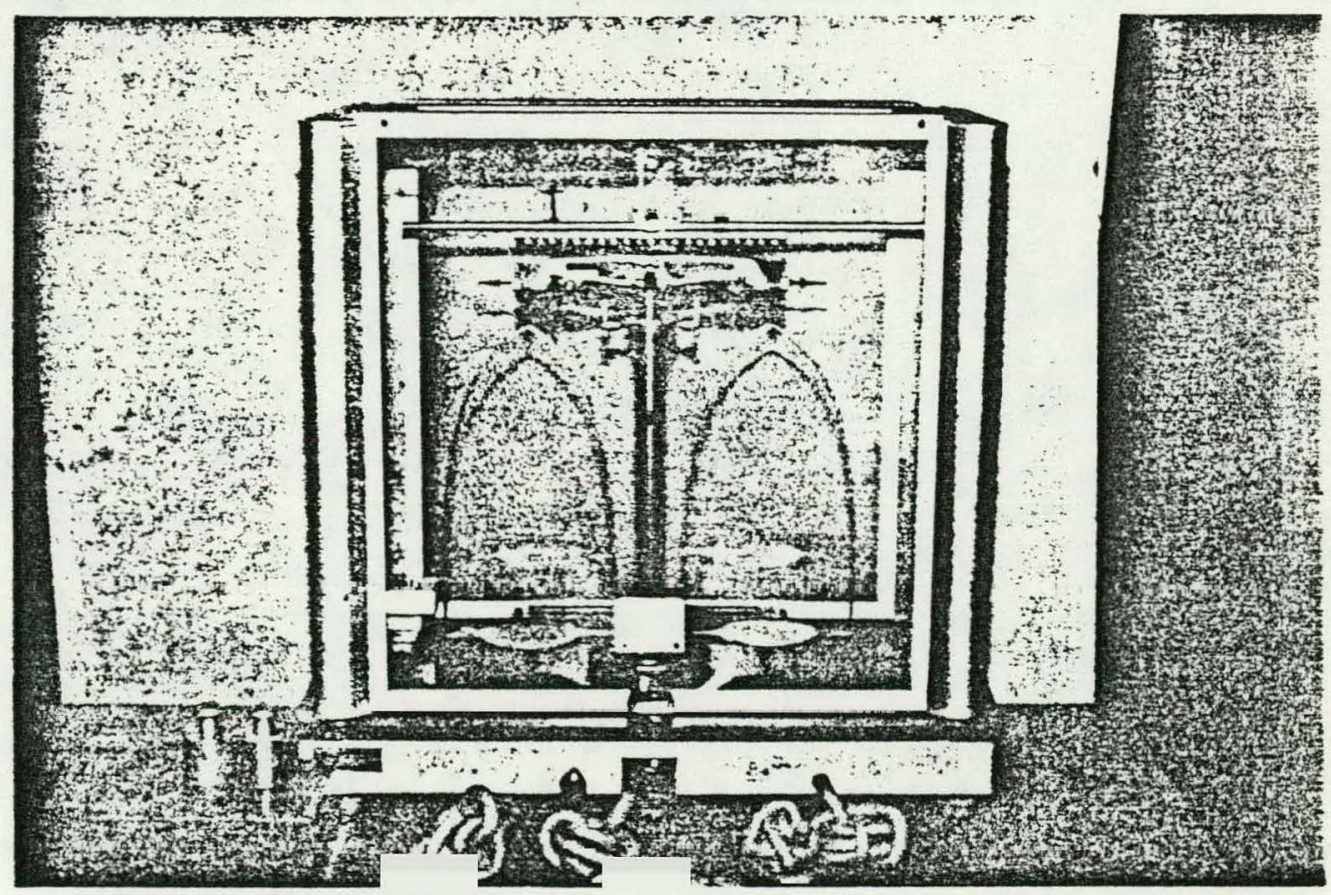

Fig. 5: Analytical Balance and Samples 


\section{Data}

The following is a table of the data:

Weight in Grams

$\begin{array}{cllll}5 / 16 " \times 48 " & & & \\ \text { Sample } & \text { O Month } & 1 \text { Month } & 2 \text { Months } & 4 \text { Months } \\ 1 & 20.37 & 20.52 & 20.89 & 20.95 \\ 2 & 23.50 & 23.67 & 23.69 & 23.75 \\ 3 & 21.66 & 21.97 & 22.05 & 22.00 \\ 4 & 20.29 & 20.59 & 20.71 & 20.75\end{array}$

Conclusions

From the weight data it is evident that so significant amount of water absorption is occurring. It is postulated that the slight increase is caused by water absorption in the ends of the tube and a few open cells along the sides of the tube. 


\section{Purpose}

A test to determine the change in volume with increased pressure of the compressible element was conducted. This test was conducted to better understand the mechanism of the freeze protection so that an optimium size could be selected instead of being restricted to standard manufactured sizes (special dies must be made to accomodate non-standard sizes). It is very important to use the minimum safe diameter so as to reduce fluid frictional losses which increase pumping requirements.

\section{Procedure}

The test apparatus, shown in the attached figures consists of a sample compression chamber, a pressurizing cylinder, a calibrated pressure cylinder drive and a pressure gauge. Samples of the "compressible element 24" long were placed in the compression chamber which consisted of a sight glass. All the air in the system is purged and replaced by hydralic oil. The pressurizing cylinder, a 1 1/2" I.D. hydraulic cylinder, was incrementally advanced and the pressure recorded. The pressure was increased up to about 100 psig. The pressure was then reduced to below 0 psig, the sample allowed to expand back to its normal state, for a few minutes and then the pressure adjusted to 0 psig and the test was repeated several times for each sample. 

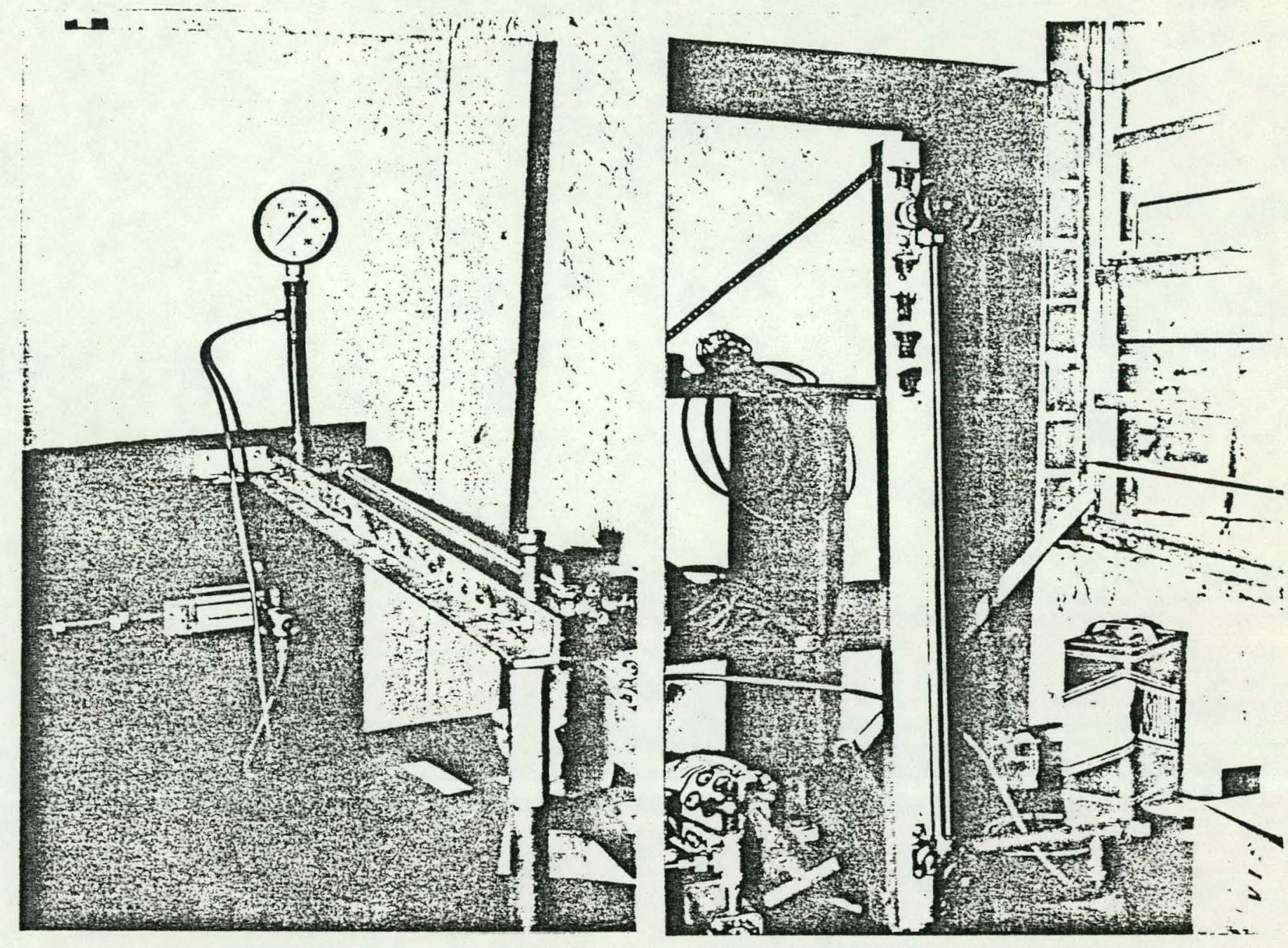

Fig. 6: Compressibility Test

Apparatus. Note hydraulic cylinder and actuator as well as Bourdon tube guage for pressure indication.

Fig. 7: Sample in Compressibility Test Apparatus. Note that glass pipe allows direct observation of effect of pressure on the test article. 
One sample of the $3 / 80 . D$. and three of the $5 / 16^{\prime \prime}$ compressible samples were run. Computer-generated graphs show the test results on each run conducted on the four samples.

\section{Conclusion}

The samples compressed uniformly between 0 and $30 \mathrm{psig}$, above $30 \mathrm{psig}$ the rate of compressibility exponentionally increased. At very high pressure it is suspected that there were errors introduced by unaccounted for expansion and deformation of various pieces of the test apparatus, particulariy the incrementally calibrated pressure cylinder drive.

One may conclude that the compressible element is adequately modeled as air enclosed in an incompressible element. 
STRAIN ANALYSIS

A series of experiments to measure the strain induced in sample tubes during freezing was carried out during July, 1980. The samples were 18 inch lengths of $5 / 8$ inch copper $A C R$ tubing with a $5 / 16$ inch diameter silicone foam insert used as the compliant core.

The initial tests were designed to provide a gross measure of the circumferential strain in the tube during the freezing process. The approach was to construct a simple electrical resistance strain gauge by wraping several hundred turns of 40 AWG varnished copper magnet wire around the tube in a uniform manner. The wire was bonded to the tube by means of glyptol cement and in this way was subjected to an axle strain that was equal to the circumferential strain in the tube. The complete assembly had a resistance of about 50 ohms and was configured in a wheatstone bridge circuit to sense the strain induced resistance change. A small $50 \mathrm{ohm}$ spool of identical wire was used in an adjacent bridge arm for temperature compensation (dummy gauge). Both the sample and dummy spool were then placed in a freezer and cylced through freeze-thaw cycles. In spite of the careful design, the strain gauge apparatus proved overly sensitive to temperature changes, especially the differences during chill-down between the tube and spool caused by their different thermal masses. Wire made of constantan, which has a very small temperature coefficient of resistance, would alleviate the problem but was not available for these tests. 
A second series of tests was made but in this case the crude wire gauge was replaced with a commercially available foil strain gauge (Micromeasurements CEA series gauges). A BLH laboratory electronic strain indicator was used to measure the strain. Temperature compensation was accomplished by using gauges specified for use with copper and by employing a strain free dummy gauge subjected to the same conditions as the sample under test.

A sample with gauge attached was placed in a freezer to verify adequate temperature compensation. The sample was then filled with water through an attached valve and frozen with core in place. A container of water was adjacent to the sample during freezing as a visual indicator. The analog output of the strain indicator was monitored with a strip-chart recorder during the freezing process.

No significant change in the circumferential strain in the tube were detected during the freezing process. Strains of 100-300 microstrain were observed but these readings were determined to be within a range that could be due solely to temperature effects. Strain levels approaching yield values for copper are roughly ten times as big. The conclusion from this test was that under the given conditions, no significant strains were developed in the tube during the freezing cycle.

In retrospect, this experiment is seen to be inadequate since the water pressure at onset of freezing was atmospheric pressure or less. If future research is possible, it should be done with the test article pressurized to simulate actual line pressures. A rather complex apparatus is necessary for such a test and time and budget constraints have prohibited the attempt. 
ABSORBER FREEZE TEST

Purpose

A scaled up proof of concept test had to be conducted to determine if the same phenomenon that occurred in the small scale freeze test would occur in a full scale absorber. This will also permit close inspection of the absorber plate after each successive freezing without having to disassemble an entire collector. Testing just the absorber would reduce the time required to freeze the absorber and also reduce the size of the freeze testing chamber.

\section{Description}

The full scale absorber consisted of a $3^{\prime} \times 8^{\prime}$ piece of 16 oz. sheet copper. To the copper sheet, I/2" I.D. Type $L$ annealed copper was soldered. The solder used was $95 \%$ tin and $5 \%$ antimony. This solder was selected for its relatively high softening point of $450^{\circ} \mathrm{F}$. The copper tubing was attached in a serpentine pattern parallel to the long side of the copper sheet.

A problem occurred in soldering the copper tubing to the sheet. The problem was severe warpage of the sheet. Its thinness relative to that of the pipe caused it to overheat and severly deform into waves. A special steel table with arms to anchor the tubes to the sheet was constructed. This worked successfully. 
After assembling the absorber, two thermocouples were attached to the absorber: one on the plate midway between the tubes (about 6-7" on center) and one directly on a tube in the middle of the absorber. These were used to determine if freezing occurred.

At the inlet of the absorber a device was constructed that would hold the compressible element in place and also permit water line pressure to be maintained on the absorber. At the outlet of the absorber a plug cock was installed to maintain water line pressure on the absorber during testing.

The installation of the compressible element was a challenging task as there is $50^{\prime}$ of $1 / 2^{\prime \prime}$ I.D. tubing soldered to the $3^{\prime} \times 8^{\prime}$ copper sheet and there are 5 - $180^{\circ} 6^{\prime \prime}$ diameter turns. This was accomplished by affixing a high volume low pressure vacuum system (a "shop vac") to the outlet of the absorber. An appropriately sized rubber ball with a string attached was fed into the inlet pipe. The suction easily drew the ball with attached string through the entire $50^{\prime}$ of pipe.

The string was then tied to the compressible element and slowly drawn through the pipe. A friction reducing powder (talcum powder) was employed as the friction of drawing the clean silicon rod through the $5-180^{\circ}$ bends became excessive.

After the compressible element was installed and secured, the water line was connected and the system flushed of air. The compressible element stretched about $2^{\prime}$ by the water rushing past it and out the absorber outlet. The $2^{\prime}$ of stretched silicon rod retreated a few inches when the water was turned off. The remaining was cut off when the outlet cock was closed. 
The freeze protected, flushed and pressurized absorber panel was then placed in the absorber and freeze chamber that was specially constructed. It is described in the next section.

\section{Procedure}

The panel was marked every two feet along the pipe and at 3 places around each of the $5-180^{\circ}$ turns. Each spot was measured with calipers the nearest $.001 "$. This measurement was repeated after the panel thawed after each successive freeze cycling.

Freezing was determined to have occurred when the reading from the themocouple mounted on the pipe on the absorber plate indicated a temperature of less then $30^{\circ} \mathrm{F}$ for over an hour. The panel typically required 3 hours to freeze, it was typically kept frozen for at least 3 additional hours.

Results

The water line pressure at the test facility was about 60 psi, the absorber piping was initially subjected to this pressure. The tubes showed significant swelling after the first freeze cycle and ruptured in 3 places after the second cycling. Ruptures occurred in the region of the $180^{\circ}$ bends.

It was deduced that the line pressure collapsed the silicon rod to such an that no room remained to accomodate date expansion from phase change of the water. This result verifies the theoretical analysis. 


\section{FREEZE TEST CHAMBER}

The freeze testing chamber for the full scale assembled absorber plate was to be at a commercial frozen storage business. A detailed examination of the costs associated with pursuing this approach showed they would appreciably exceed the funds for this aspect of the project. It was decided that a crude freeze chamber would be constructed at the site where the other related tests were conducted.

\section{Description}

The chamber was constructed of wood to have an internal cavity $31 / 2^{\prime \prime}$ high, $45^{\prime \prime}$ wide, and 105" long. On top of this chamber a plenum $31 / 2$ " deep, 24" wide, and 90" long was constructed. The entire assembly was mounted on legs and insulated with 2 " of expanded polystyrene. Two small "muffin" fans were placed in the plenum which was ducted to the main freeze chamber. The freeze protected absorber plate was placed in the large chamber and made air tight. It was then flood with water and pressurized to a predetermined level.

\section{Procedure}

The plenum was filled with 25 lbs. of dry lce, sealed air tight and the fans turned on. The fans circulated the very cold air and carbon dioxide gas around the absorber plate. The absorber plate was shimmed up from the bottom of the freeze chamber for better air circulation and more rapid freezing. 

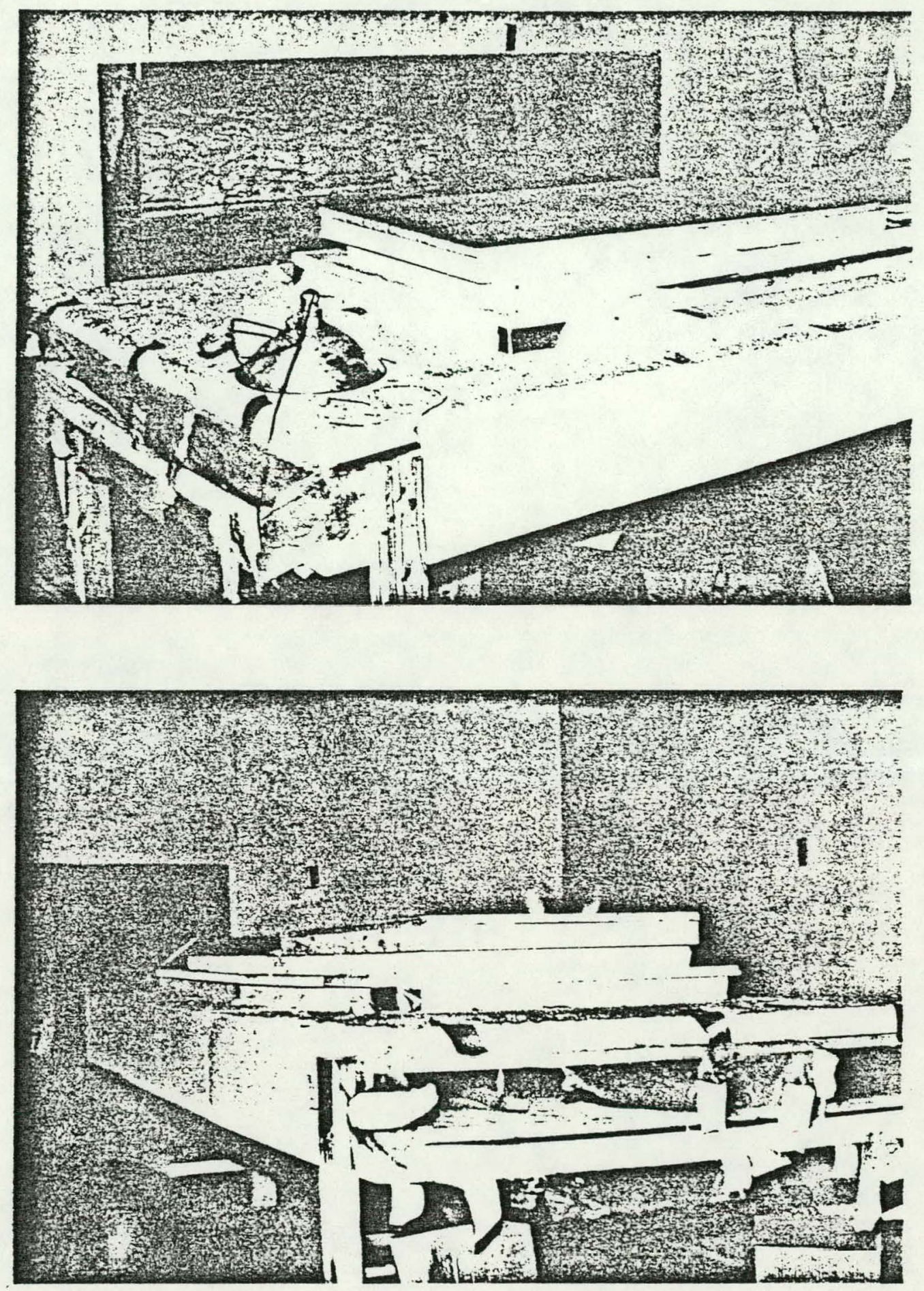

Fig. 8 \& 9: Absorber Freeze Test Chamber. Note thick expanded polystyrene insulation, elevated dry ice chamber and plenum and absorber plate chamber. 
Two thermocouples were soldered to the absorber plate, one on a tube and one centrally placed between two tubes. These were monitored with an electronic themocouple meter. The freezing process was visually monitored until the termocouple on the tube recorded a temperature below $30^{\circ} \mathrm{F}$ for over an hour. At this point, the water in the absorber was assumed to be frozen. To verify this the valve on the absorber was opened to see if any flow occurred. If none flowed the fans were run all night to consume the dry ice. The following day the panel would be removed while still under pressure and measurements taken of tube diameter in 35 locations on the absorber plate. These same points had all been recorded with the plate pressurized just before the initial freezing occurred. Also a control copper tube 30 " long was included with each freeze cycle. It was filled with water and not freeze protected. Swelling was positive proof the absorber had also frozen during the cycle. This cycle was repeated until failure occurred in the absorber.

The first test set was conducted with the absorber plate subjected to 76 psig. The second set with the plate at 10 psig and the third at 15 psig. A sketch shows the locations of the measurement points and a table lists the readings that were taken after each freeze cycle as well as the initial measurement. When a rupture occurred, the compliant member was removed, the holes brazed shut with $5 \%$ Ag Sil-Fos brazing alloy, leak tested and the compliant member replaced. Removal and replacement are much more difficult in a wet absorber than in a dry one. 
Results

The results proved the concept correct but brought to light the effect of initial water pressure. With the absorber plate at line pressure, severe swelling was noted after the first freeze cycle. This seemed to occur particularly at the $180^{\circ}$ bends in the pipe. No rupture occurred but it was obvious that it was imminent. A second freeze cycle bore that observation out as ruptur occurred in three regions along with additional overall swelling.

It was clear from this test that the city line pressure was compressing the compliant member to such an extent that all the compressibility was consumed by the water pressure. As line pressure was obviously excessive for the chosen insert, the pressure was reduced to $10 \mathrm{psig}$ and increased in subsequent tests until swelling again occurred. The tube was repaired and the freeze cycling continued.

The absorber was cycled three times at 10 psig with no measureable or observable expansion. The pressure was increased to 12.5 psig and cycled with the same result. The pressure was increased to 15 psig and cycled, this time noticeable swelling occurred at 2 bends between measured points. On the second freeze cycle, rupture occurred in two locations. 


\section{Conclusions}

The conclusions for this test were that for the compliant member selected the maximum permissible line pressure that this absorber plate could safely be subjected to without freeze damage occurring was over 10 psig but somewhere below 15 psig. This would restrict this type absorber to systems with very low line pressure, such as European style systems with roof mounted, vented holding tanks. To accommodate high line pressures, a different compliant member would have to be designed as described in the previous section on mathematical analysis.

Importantly, the concept was verified in principle and demonstrated in practice for low-pressure systems. 


\section{PROTOTYPE TESTING}

\section{Description}

The absorber freeze test having been successfully completed, a operational solar water heater test set up was constructed. The assembly was built at the south end of the building where the previous experiments had been conducted to facilitate access to tools and other necessary supplies and equipment. It consisted of an elevated commercially available water heater inside the building and solar panel utilizing the inherent freeze protection outside the building.

The solar panel was constructed from the absorber plate used in the absorber freeze test. The plate was encased in a rectangular box made of fir approximately $3^{\prime}-4^{\prime \prime} \times 8^{\prime}-1 " \times 31 / 2^{\prime \prime}$. The rear of the modular solar collector was made from a sheet of double foil faced isocyanurate insulating board approximately 1/2" thick. The glazing is a sheet of 0.040 " corregated Filon. The constructed box contained the copper plate and tube absorber painted flat black with exhaust manifold paint. The collector box was made waterproof and mounted in a wooden test frame. The frame was placed against the south wall of the building so that exterior pipe runs were reduced to a minimum as these pipes would have to be freeze protected in the same manner as the solar collector's absorber plate. All exposed wood on the frame and collector box were painted for protection from the elements. 


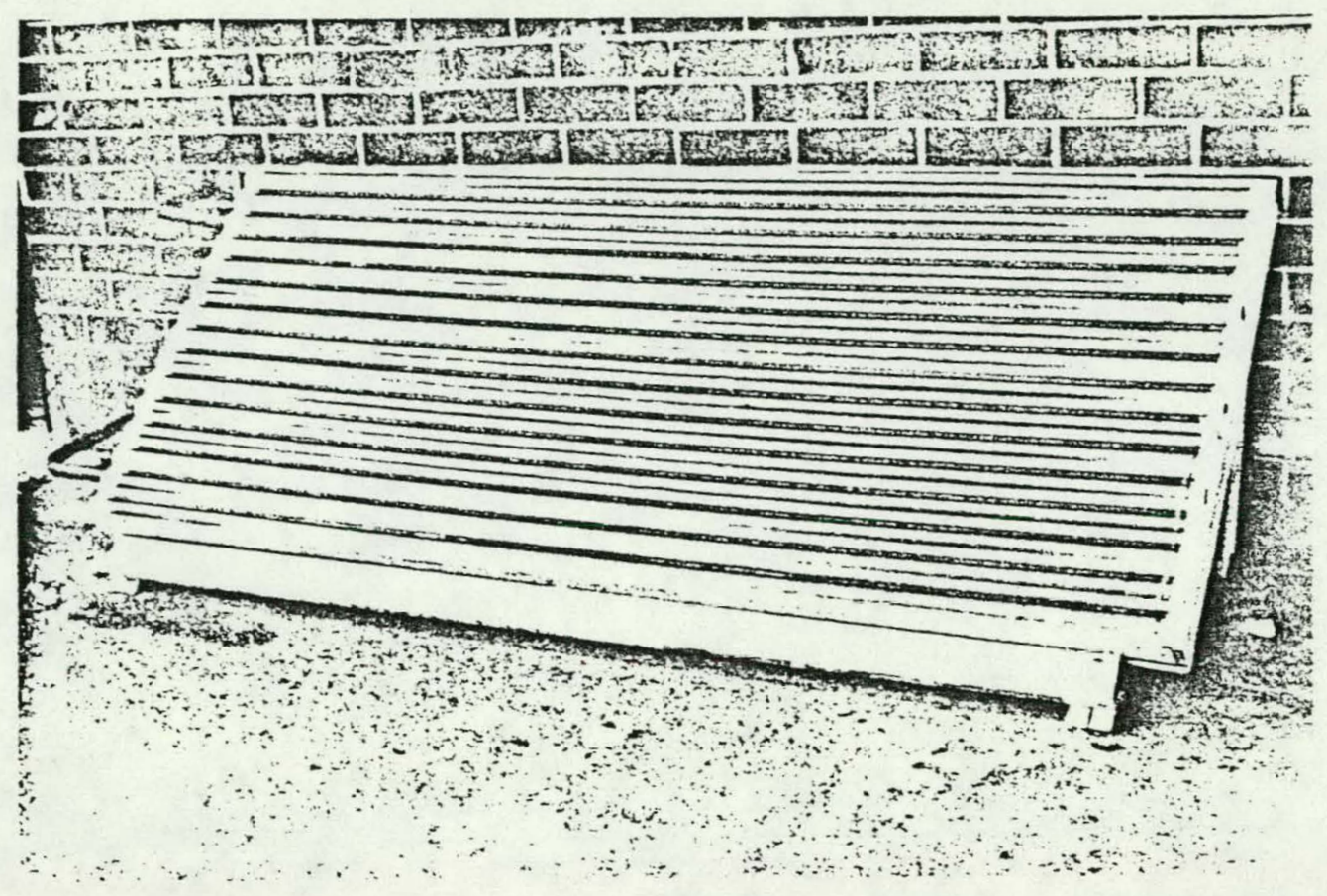

Fig. 10: Prototype Panel Installed. Unit is single-glazed with corrugated Filon.

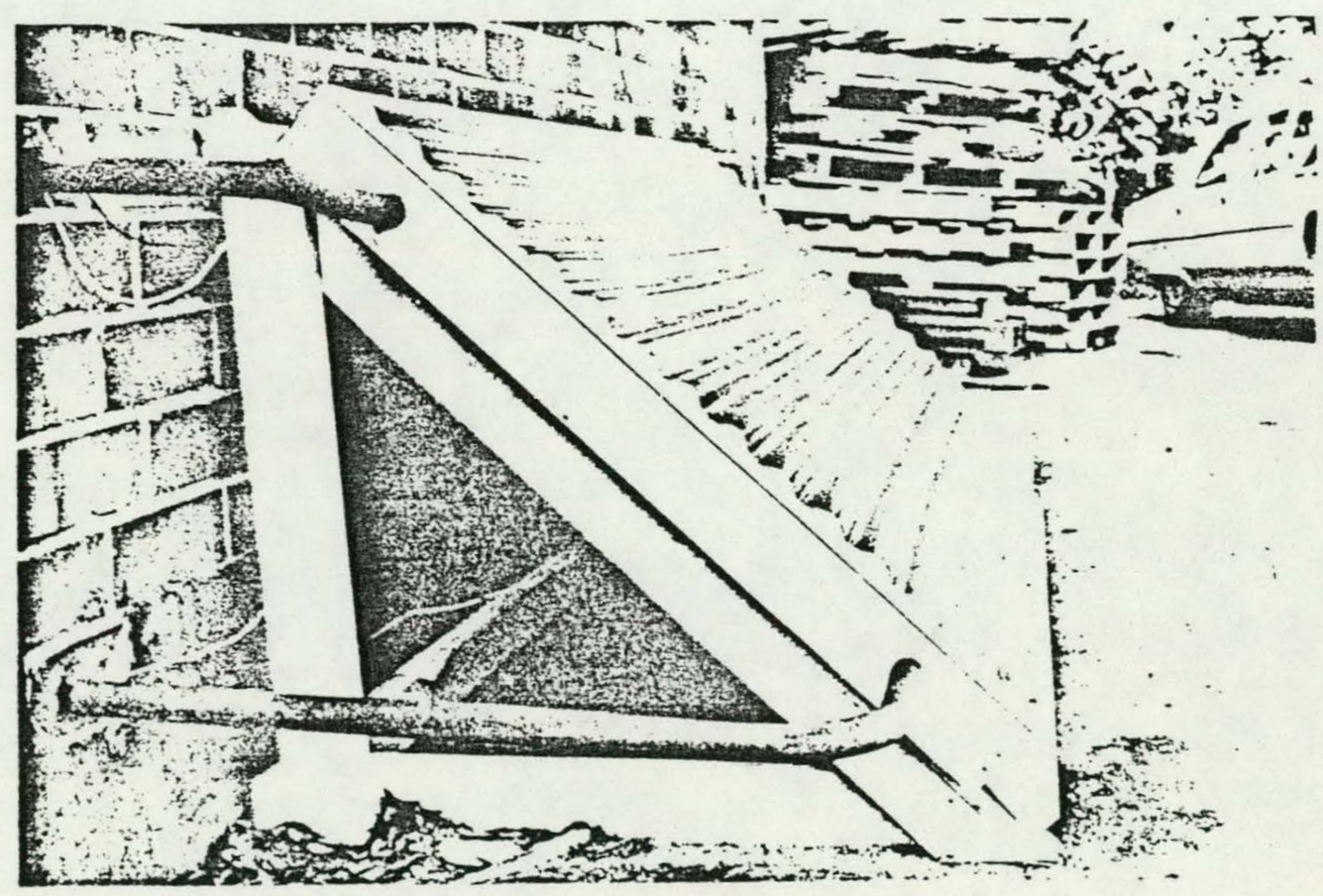

Fig. 11: Supply (lower) and Return Piping to Collector. These insulated lines also are freeze-protected. 


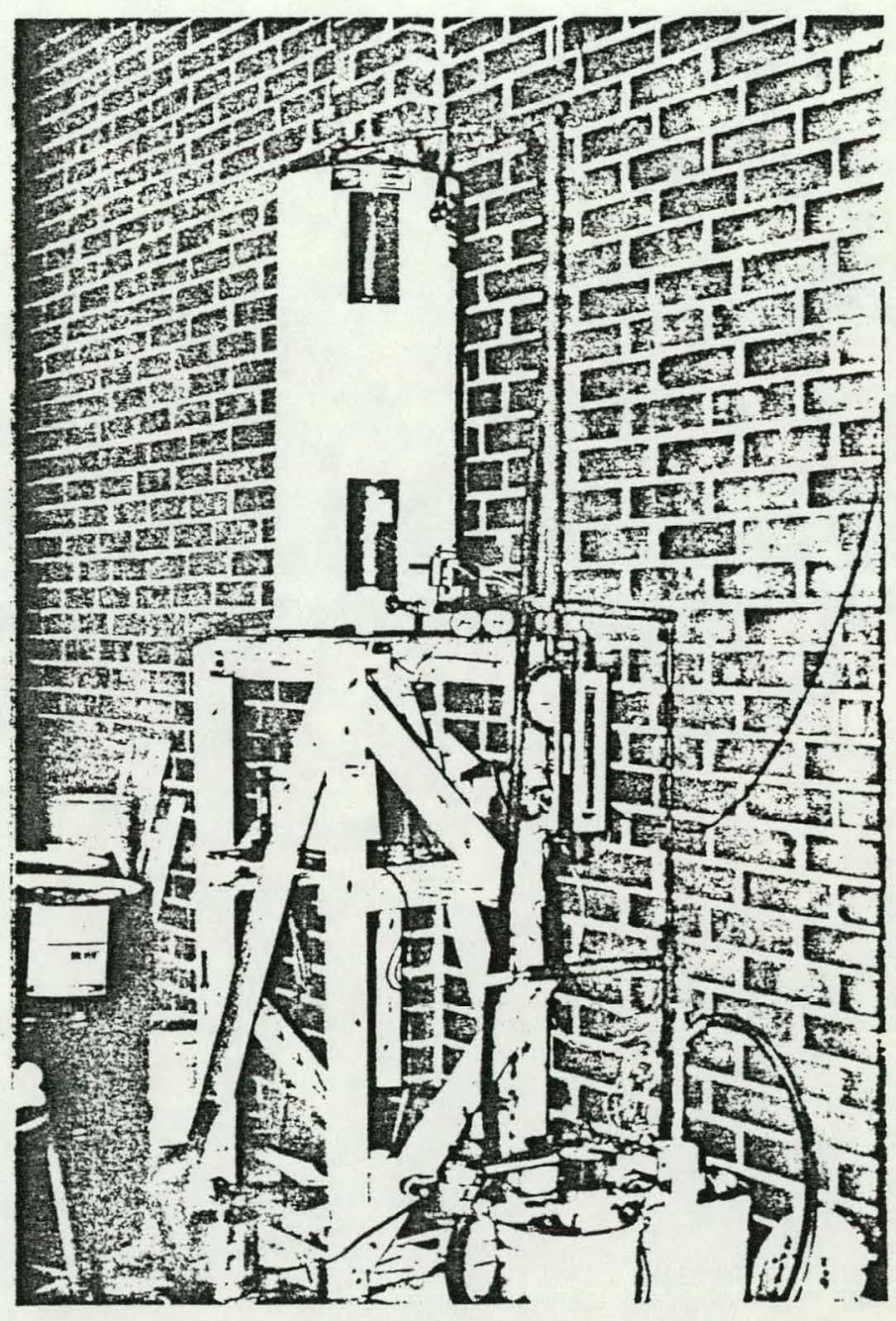

Fig. 12: Inside Components of Prototype System. Chart recorder is below DHW tank. Rotometer is in return line. Thermocouples with electronic ice points are in tees of supply and return lines. Other instrumentation include watt-hour meter, dial indicating thermometers, pyranometer and elapsed-time meter. 
The hot water tank was mounted inside the building directly behind the wall where the solar panel was located. The storage tank, a 40 gallon electric hot water heater, was placed on a wooden platform about 54 " above the floor. This was done to facilitate a future experiment for testing the solar water heater in a thermosyphon mode. This also kept between 7 and $10 \mathrm{ft}$. of water head on the absorber. The tank and collector were connected in a conventional manner with a minimum of piping. The drain cock from the bottom of the tank was removed and the circulation pump and drain valve were connected. This fed the bottom of the collector after penetrating the wall. The pipe coming from the top of the collector was connected to the cold water inlet at the top of the tank. The cold water dip tube was cut to reach about $60 \%$ of the way to the bottom of the tank. The pressure regulated fill valve was connected to the hot water inlet. The pressure and temperature relief valves were connected in the conventional fashion. After filling the tank a vent line was installed to insure that as the water in the system expanded it would overflow the tank into a container. This prevented the system from becoming overpressurized due to heating.

The collector fluid circulating pump is connected to a differential temperature controller. The controller senses the temperature of the bottom of the tank and the middle of the absorber plate. When the absorber is $18^{\circ} \mathrm{F}$ hotter than the tank, the collector pump is turned on, it remains on until that temperature difference decreases to $3^{\circ} \mathrm{F}$ or below. 
All piping used in the system is type L.1/2" I.D. copper tubing. It is insulated with $1 / 2^{\prime \prime}$ wall Rubatex expanded rubber insulation that is conventionaliy used to insulated refrigeration lines and some indoor piping systems. The piping that leads to the collector is installed with a capped "tee" in both the supply and return lines. These provide access to the inner passage ways of the tubing and collector outside of the conditioned space, i.e., the building. Through the inlet "tees" the $5 / 16$ " foam silicone cord was fed, when it came out the outlet "tee," a distance of about 50 feet, the ends were suitable, attached and these access parts capped.

A rotometer was connected to the return line from the collector so that flow quantities could be monitored and collector efficiency estimated. Temperature sensors, both dial indicating and thermocouples, were installed in the supply and return line for temperature monitoring. The tank was filled with water, power connected to the pump and controller, and the system put into operation. The only method for freeze protection is the inherent provided by the internal compliant member.

The system operated through the winter of 1980-1981 and is still operating with no sign of collector failure or damage as of this writing, May, 1981. 


\section{COMPONENT LIST}

Collector Circulating Pump

Differential Temperature Controller

Controller Sensors

Electric Water Heater, 40 Gallon

Piping

Pipe Insulation

Collector Absorber Sheet

Collector Absorber Coating

Collector Glazing

Collector Insulation

Collector Frame
Marsh Mod. No. 809-01

Honeywell R7412

Honeywell $\mathrm{C} 773$

B/W Corp. Mod. No. A4055Q

1/2" I.D. Type L

1/2" wall, 5/8" 0.D. Rubatex

16 oz. Copper

Flat Black Paint

0.040 " Filon

1/2" Foil Faced Thermax

$3 / 4 "$ Fir

A variety of instrumentation was used to monitor the operation of the system. A radiometer was used to obtain instantaneous readings of the sun's intensity. A strip chart recorder took continuous readings on two channels. For a short period, the solar insolation was continuously recorded along with the temperature difference of the inlet versus the outlet of the collector. As mentioned before, a rotometer was installed in the collector loop to monitor mass flow in the loop.

Electrical consumption of the pump was monitored by a utility type watt hour meter and the pump run time which was recorded daily was kept on a elasped time meter. This instrumentation documented the fact that the system on a sunny cold day would fully charge the 40 gallon tank to about $130^{\circ} \mathrm{F}$ from an initial temperature of approximately $50^{\circ} \mathrm{F}$. 


\section{INSTRUMENTATION LIST}

Strip Chart Recorder

Channel A \& B Amplifiers

Thermocouple

Cold Junction Compensator

Radiometer

Multimeter

Rotometer

Watthour Meter

Elapsed Time Meter

Thermometers

Weight Balance
Hewlett.Packard 71008

Hewlett Packard 17500A

Omega CPSS-18G-6 inch

Omega Model MCJ

Epply PSP

Fluke $8024 \mathrm{~A}$

Brooks Instr. Mod. No. 1110-08 H2GIA

G.E. CL200/240V/3W/FMZS

Hobbs Mod. No. 20035

Ashcroft $0-250^{\circ} \mathrm{F}$

Will Corporation

\section{Thermosyphon}

The system operational test was designed for future adaptation from forced circulation to themosyphon operation, use of the convective forces driven by temperature differences to control fluid flow through the collertor and storage.

In mid-February, the original temperature differential controllers, not one made by Honeywell, failed so that the pump never ran. The system was noticed to continue in operation by a temperature rise as indicated by the thermometers and a marginal flow indicated by the rotometer. The flow rate was at the very lower limit of the rotometer's scale. The system was 
monitored during a very clear period which extended over approximately 10 days. During that time, the storage tank reached a maximum temperature of $145^{\circ} \mathrm{F}$. No tank draws were taken, the only losses that occurred were stand by losses. The interior of the building in which the storage tank was located was not heated in the evening. The tank would lose about 30 to $40^{\circ} \mathrm{F}$ overnight depending on tank temperature and ambient temperature.

This thermosyphon action occurred with the pump still in the circuit along with the rotometer. These cause large pressure drops in the piping with respect to those that nomally occur in a thermosyphon system. This conclusively proved that the inherently freeze protected solar collector could operate well in the natural convection mode even though the tubing in the absorber and some of the external piping had its flow resistance increased by the compliant member being located within the piping.

\section{Continuous Operation}

The system was put into operation in September, 1980. The instrumentation on the system was added slowly and at different times as the project continued. The collector was kept flooded with water by the unpressurized elevated storage tank, the base of which is 54" above the bottom of the collector. The collector is 3 feet wide and is mounted at $45^{\circ}$ from the horizontal. All the copper tubing that is in the collector, outside the building, in the wall, or within 2 feet of the wall inside the building is freeze protected by the compliant silicon rod. 
The system operated for approximately three weeks until the first freeze, which was a very "soft". freeze. No damage occurred. The months of November and December were also mild with only a few days of temperatures below $32^{\circ} \mathrm{F}$. January and February of 1981 had many days of freezing weather with one particular cold period. See table of weather data.

During the entire winter and spring of this test period no noticeable damage was caused to the absorber or exposed piping. The collector was not dismantled and closely examined for deformation because the decision was made to operate the system continuously until either failure from freezing or some other cause occurred. The current plan is to operate the system indefinitely at its current location and continue to monitor the system in a reduced capacity.

The pump which forced water through the system maintained a flow rate of 0.62 GPM seemingly indifferent to the temperature of the fluid it was moving. Around solar noon with tank temperatures relatively elevated, an average temperature rise of about $8^{\circ} \mathrm{F}$ was recorded. This of course varied with tank temperatures, insolation, and ambient temperature.

During periods when no water was drawn from the tank, the outlet of the $24 \mathrm{sq}$. ft. collector was typically 160 to $170^{\circ} \mathrm{F}$ towards the end of the day with a smal1, $2-4^{\circ} \mathrm{F}$ temperature rise across the collector. 
On several occasions the tank was drawn down in the mornings, typically on the weekend to wash something, the collector would be discharging $130-140^{\circ} \mathrm{F}$ water with an inlet temperature of $125-135^{\circ} \mathrm{F}$. This one collector would heat the tank from $55^{\circ} \mathrm{F}$ to $130^{\circ} \mathrm{F}$ on a clear day.

The only problems encountered with this system was the aforementioned failure of an electronic controller. The system went into thermosyphon control and performed with no mechanical moving parts or any electricity. 


\section{DESIGN REVIEW}

This project demonstrated the effectiveness of inherent freeze protection. It is notable that the system operated well under both active and thermosyphon circulation.

It was anticipated that difficulties could arise in insulating the compliant element in the collector; however, in practice no real problem was encountered using the serpentine -tube collector carefully located near the hot water tank.

Work is needed in at least three areas:

(1) Since the current technique is suitable only for low-pressure systems, a method is needed to produce a compliant element which encapsulated a higher-pressure gas. A continuous tube is not felt practical since a pinhole leak would fill the entire air space. A creative solution must be sought.

(2) Long-term experience in material reliability is mandatory. The water absorption and compressibility tests need to be upgraded in sensitivity and continued.

(3) More field experience is needed to discover any generic problems that would limit implementation. It would be desirable to identify low-pressure applications so that the current techniques can be used. We are discussing this approach with an interested party. 
ABSORBER PLATE TEST DATA

Pre Initial Post
Freeze Freeze $\begin{gathered}\text { Post } \\ \text { Freeze }\end{gathered}$

$\begin{array}{lllllllll}1 & .625 & .625 & .627 & .629 & .631 & .630 & .621 & .629 \\ 2 & .616 & .643 & .642 & .642 & .642 & .641 & .645 & .643 \\ 3 & .619 & .619 & .619 & .619 & .619 & .620 & .620 & .620 \\ 4 & .620 & .623 & .624 & .624 & .614 & .614 & .625 & .624 \\ 5 & .611 & .705 & .720 & .706 & .704 & .705 & .707 & .708 \\ 6 & .597 & .603 & .603 & .606 & .605 & .605 & .603 & .604 \\ 7 & .615 & .625 & .652 & .650 & .653 & .649 & .645 & .650 \\ 8 & .622 & .622 & .622 & .622 & .622 & .622 & .621 & .622 \\ 9 & .620 & .621 & .622 & .622 & .621 & .621 & .621 & .620 \\ 10 & .621 & .629 & .627 & .628 & .627 & .628 & .629 & .628 \\ 11 & .615 & .687 & .731 & .778 & .775 & .775 & .775 & .780 \\ 12 & .594 & .613 & .612 & .616 & .614 & .612 & .613 & .614 \\ 13 & .619 & .652 & .651 & .651 & .651 & .651 & .651 & .613 \\ 14 & .618 & .629 & .630 & .630 & .631 & .629 & .630 & .653 \\ 15 & .617 & .615 & .617 & .617 & .616 & .617 & .616 & .629 \\ 16 & .616 & .617 & .618 & .617 & .618 & .618 & .618 & .617 \\ 17 & .608 & .645 & .718 & .718 & .719 & .719 & .719 & .716 \\ 18 & .598 & .648 & .681 & .674 & .679 & .690 & .680 & .680 \\ 19 & .607 & .694 & .724 & .729 & .725 & .713 & .713 & .735 \\ 20 & .611 & .614 & .615 & .616 & .616 & .615 & .615 & .615 \\ 21 & .608 & .621 & .621 & .621 & .620 & .619 & .620 & .622 \\ 22 & .611 & .629 & .626 & .626 & .628 & .627 & .627 & .626 \\ 23 & .608 & .702 & .702 & .700 & .701 & .701 & .700 & .703 \\ 24 & .584 & .600 & .652 & .657 & .657 & .661 & .660 & .656 \\ 25 & .618 & .624 & .638 & .638 & .637 & .637 & .637 & .640 \\ 26 & .613 & .665 & .665 & .667 & .667 & .667 & .667 & .669 \\ 27 & .613 & .615 & .614 & .613 & .614 & .615 & .614 & .613 \\ 28 & .615 & .628 & .627 & .628 & .628 & .628 & .628 & .626 \\ 29 & .613 & .694 & .692 & .700 & .698 & .698 & .698 & .680 \\ 30 & .594 & .619 & .629 & .625 & .628 & .626 & .626 & .630 \\ 31 & .601 & .630 & .621 & .622 & .621 & .622 & .622 & .623 \\ 32 & .615 & .651 & .631 & .629 & .633 & .629 & .629 & .633 \\ 33 & .618 & .620 & .619 & .619 & .619 & .619 & .619 & .620 \\ 34 & .610 & .651 & .653 & .619 & .619 & .619 & .619 & .620 \\ 35 & .619 & .624 & .622 & .620 & .624 & .625 & .625 & .619\end{array}$




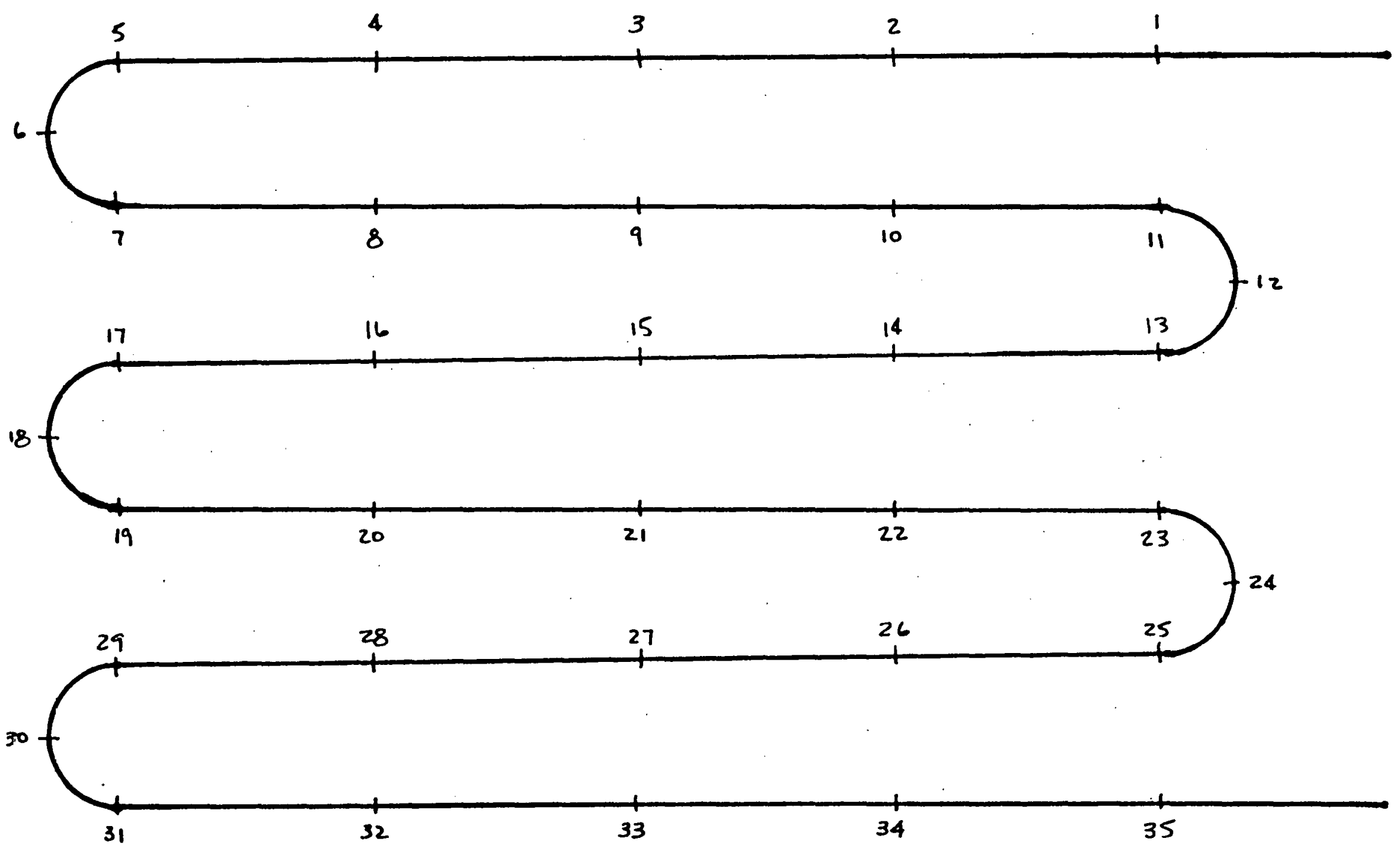

LOCATION OF ABSORBER PLATE FREEZE TEST MEASUREMENT POINTS 
TABLE OF WEATHER DATA

Occurrances of Freezing During Prototype Testing

December 1980

3
11
12
15
17
18
20
21
22
23
25
26
27
28
31

January 1981

2

4

5

6

7

8

10

11

12

13

14

15

16

17

18

19

24

31
Daily Minimum $T$ at Hartsfield Airport

29

31

31

31

31

30

28

27

26

29

20

25

24

30

30

31

27

23

13

28

28

22

28

20

16

10

16

31

31

28

18

20

31

31

26 


\section{February 1981}

Daily Minimum $T$ at

Hartsfield Airport

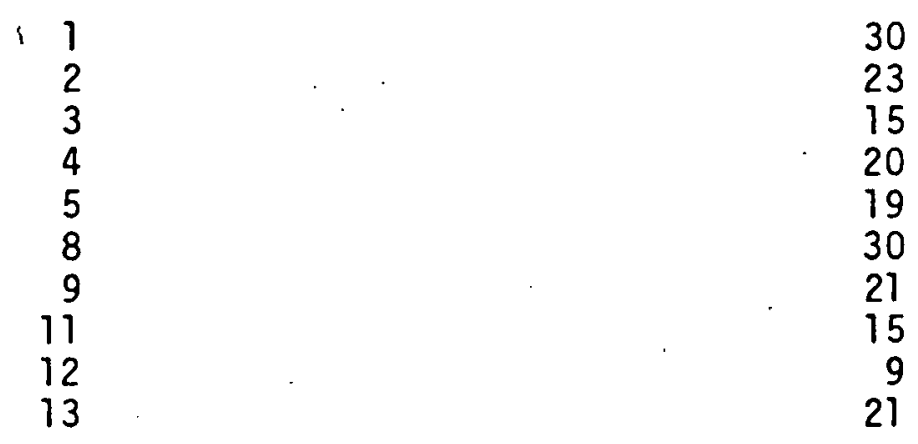

March 1981

19

30

20

29 